\title{
(Inter)disciplinaridade e transversalidades: o projeto de formação superior da Universidade Federal do ABC
}

\section{(Inter)disciplinarity and transversalities: UFABC's higher educational program}

Allan Moreira Xavier ${ }^{1}$. Leonardo José Steil ${ }^{1}$. Jesus Pascual Mena-Chalco ${ }^{2}$

\begin{abstract}
Resumo: Interdisciplinaridade é um dos principais enunciados que atravessam e nominalizam o currículo do Bacharelado em Ciência e Tecnologia (BC\&T) da Universidade Federal do ABC (UFABC) cujos agenciamentos estão em constante devir: molecular e molar. Com intuito de compreender como se dão as relações curriculares no projeto pedagógico e quais os regimes de verdade apresentados na idealização e na execução desse projeto no que trata dos enunciados de interdisciplinaridade, realizou-se um levantamento arqueológico dos discursos para a análise deles na perspectiva foucaultiana, com entrevistas semiestruturadas, documentos oficiais (projetos pedagógicos, normativas e legislação) e grafos elaborados a partir das ementas das unidades curriculares. A compreensão de que a interdisciplinaridade, em sua derivação atitudinal, é integradora de conhecimentos diverge da lógica transversal rizomática que pode ser estabelecida no exercício flexível do currículo que escapa às normatizações e produz singularidades curriculares.
\end{abstract}

Palavras-chave: Ensino superior. Currículo. Interdisciplinaridade. Análise do discurso.

\begin{abstract}
Interdisciplinarity is one of the main statements that identifies the curriculum of the Bachelor of Science and Technology (BC\&T) of the Federal University of ABC (UFABC) whose courses are steadily becoming molecular and molar. We sought to understand how to provide curricular relationships in this project and to see which regimes of truth are presented in the design and implementation of such project when it comes to interdisciplinarity. A historical survey of speeches was made and discourse analysis from a Foucauldian perspective from semi-structured interviews, official documents (pedagogical projects, normatives and legislation) and graphs drawn from the summaries of courses was carried out. We realized that interdisciplinary in its attitudinal derivation, and is an integrator of knowledge. This differs from the logic that can be established in the exercise of a flexible curriculum that escapes the norms and produces curricular singularities.
\end{abstract}

Keywords: Higher education. Curriculum. Interdisciplinarity. Discourse analysis.

\footnotetext{
${ }^{1}$ Universidade Federal do ABC (UFABC), Centro de Ciências Humanas e Naturais, Santo André, SP, Brasil. E-mail: <allan.xavier@ufabc.edu.br>.

${ }^{2}$ Universidade Federal do ABC (UFABC), Centro de Matemática, Computação e Cognição, Santo André, SP, Brasil.
} 


\section{(Inter)disciplinaridade}

Manifestos por formações em nível superior interdisciplinares já circulavam no Brasil quando da elaboração e execução do projeto pedagógico da Universidade Federal do ABC (UFABC) - o que, de certa maneira, desloca a inovação do projeto da universidade do conceito de interdisciplinaridade. Como exemplo, Zucco, Pessine e Andrade (1999) discutiam que a formação clássica disciplinar com ênfase na especialização pouco contribui para a resolução dos problemas contemporâneos, principalmente porque dificultam ou inexistem as necessárias articulações e diálogos entre os variados campos do conhecimento, mas também porque estabelecem meta-narrativas de formação. Nos Estados Unidos, entre os anos de 1975 e 2000, um aumento de aproximadamente $250 \%$ de formados em programas interdisciplinares é contraposto ao aumento de $18 \%$ no número de matrículas no ensino superior (KNIGHT et al., 2013). Ainda que o conceito de interdisciplinaridade não seja novo ao pensamento humano, as mobilizações estudantis na década de 1960, especialmente na França e na Itália, deram corpo ao movimento interdisciplinar reivindicando novos estatutos de escola e universidade. (FAZENDA, 1994).

O aparecimento de propostas de alteração dos sistemas de Educação Superior, na transição entre os séculos XX e XXI, na direção de programas interdisciplinares poderia indicar certo amadurecimento do conceito de interdisciplinaridade. Tal assunção não deveria ser direta dado que da década de 1960 aos dias atuais, as pesquisas e os entendimentos sobre interdisciplinaridade(s) certamente não chegaram ao consenso de um conceito, como aponta Klein (1998).

Constatadas as pluralidades de perspectivas em que se trabalha o conceito de interdisciplinaridade, assim como o modismo que o termo enfrentou entre as décadas de 1980 e 1990, Klein (1998) argumenta ser um trabalho impossível construir uma única, absoluta e geral teoria interdisciplinar. O próprio ato de definir o termo interdisciplinaridade já é polêmico haja vista a multiplicidade de estudos e olhares sobre o tema. Ao defini-lo, corre-se o risco de criar um sistema conceitual racional e fechado, nada menos interdisciplinar. No entanto, um referencial muito utilizado nos estudos de interdisciplinaridade no Brasil, Japiassú e Marcondes definem:

Interdisciplinaridade é um método de pesquisa e de ensino suscetível de fazer com que duas ou mais disciplinas interajam entre si, esta interação podendo ir da simples comunicação das ideias até a integração mútua de conceitos, da epistemologia, da terminologia, da metodologia, dos procedimentos, dos dados e da organização da pesquisa. [...] O objetivo utópico do método interdisciplinar, diante da especialização sem limite das ciências, é a unidade do saber (JAPIASSÚ; MARCONDES, 2006, p. 150).

Nesta compreensão de interdisciplinaridade, Japiassú e Marcondes (2006) identificam um método interdisciplinar que possibilita a interação entre diferentes saberes, interação essa que pode ocorrer em diferentes níveis: simples comunicação, no menor deles, até a integração plena, produzindo uma nova unidade curricular. A busca pela elaboração de teorias e explicações que sejam as mais abrangentes possíveis, reunindo em um único sistema a compreensão da estrutura e do funcionamento do universo é uma faceta da necessidade de ordem e controle social do mundo moderno. Assim, a posição epistemológica característica da modernidade entende o conhecimento pela constante hierarquização do conteúdo acumulado, daí o uso da metáfora arborescente do saber. 
Este paradigma promoveu a compartimentalização do conhecimento e deu origem às especializações do conhecimento. Esta patologia do saber, expressão utilizada por Japiassú (1976), pode ser evitada em um trabalho propriamente interdisciplinar.

Fazenda (1995), na inexistência da possibilidade de definição única de interdisciplinaridade e na presença de abordagens práticas plurais, chama de atitude interdisciplinar o esforço de professores que se valem de pedagogias inovadoras que promovam diálogo com a sociedade, a capacidade de colocar/resolver problemas. Os obstáculos mais frequentes para o desenvolvimento de uma atitude interdisciplinar são os espíritos solitários, a possibilidade de a interdisciplinaridade se tornar uma metaciência e os perigos ideológicos presentes na organização do próprio saber (FAZENDA, 1994). A comunicação clara e o estabelecimento de conceitos em comum, o uso de uma metodologia interdisciplinar e o entendimento do caráter dinâmico da interdisciplinaridade possibilitam superar estes obstáculos no desenvolvimento de uma prática interdisciplinar. O exercício da interdisciplinaridade envolve uma profunda reflexão sobre os impasses vividos pela ciência, aponta Fazenda (1994), e facilita o enfrentamento da crise do conhecimento, permitindo que se compreenda a dinâmica que a estabelece. $\mathrm{O}$ avanço é na superação das dicotomias, na busca por uma convergência de saberes.

Knight et al. (2013) definem que interdisciplinaridade, comparada a comum abordagem multidisciplinar de agrupamento de unidades curriculares para resolução de problemas que não envolvam a interação dos componentes disciplinares, é entendida como um processo, em que problemas são muito amplos ou complexos para serem resolvidos adequadamente por uma única unidade curricular, desenhando e integrando perspectivas disciplinares distintas até alcançar uma perspectiva mais compreensiva.

Veiga-Neto (1997) afirma que o insucesso do movimento pela interdisciplinaridade encontra-se na desarticulação argumentativa que sustenta discursivamente o movimento, mas também na sua fundamentação epistemológica integrativa: integração de saberes graças a novos arranjos curriculares e, eventualmente, alcançar a unidade do saber. $\mathrm{O}$ autor ainda pontua que um elogio à unidade do método deriva da perspectiva totalizante do saber. Numa situação limite, defende, o saber total é a antítese do saber disciplinar, assim, interdisciplinaridade radical pode ser compreendida uma antidisciplinaridade - situação difícil de ser compreendida na realidade escolar: ausência de estruturas curriculares baseadas em categorias.

Frente a esses diversos enunciados que estratificam as ações interdisciplinares, é avaliado, neste trabalho, como a interdisciplinaridade, uma das principais características do projeto curricular proposto pela Universidade Federal do $\mathrm{ABC}$, dentro de seu projeto pedagógico e nas suas propostas de execução, reorganizou uma lógica curricular integradora, unificadora e/ou interrelacional.

\section{Metodologias}

Para compreender melhor esse cenário, análises de discurso na perspectiva foucaultiana (FISCHER, 2012; FOUCAULT, 2013) foram realizadas nas transcrições autorizadas de entrevistas semiestruturadas - cujos principais tópicos estão apresentados no quadro 1 - realizadas com docentes (identificados LD1 e LD2), gestores (G1), idealizadores do projeto (ID) e discentes (LA1 e LA2). 
Quadro 1. Questões que balizaram as entrevistas semiestruturadas com docentes, discentes, gestores e idealizadores do projeto pedagógico da UFABC

\begin{tabular}{|l|}
\hline $\begin{array}{l}\text { A formação em um curso interdisciplinar permite que se compreendam as relações entre as } \\
\text { diferentes áreas do saber? }\end{array}$ \\
\hline As demandas sociais são motivadoras da formação científica em um curso interdisciplinar? \\
\hline $\begin{array}{l}\text { As demandas do mercado de trabalho são motivadoras da formação científica em um curso } \\
\text { interdisciplinar? }\end{array}$ \\
\hline As demandas acadêmicas da disciplina correspondem às necessidades do curso interdisciplinar? \\
\hline A química, como ciência de formação clássica, está presente no curso interdisciplinar? \\
\hline $\begin{array}{l}\text { Um curso interdisciplinar pode ser organizado sem a presença das áreas clássicas do conhecimento } \\
\text { (como a Física, a Química, a Matemática, a Biologia, a Filosofia, entre outras)? }\end{array}$ \\
\hline As aulas em um curso interdisciplinar utilizam estratégias didáticas diversificadas? \\
\hline $\begin{array}{l}\text { Avanços em produção de energia e de tecnologia podem ser beneficiados por profissionais com } \\
\text { formação interdisciplinar? }\end{array}$ \\
\hline $\begin{array}{l}\text { Um profissional interdisciplinar compreende os principais aspectos químicos em processos } \\
\text { ambientais e tecnológicos? }\end{array}$ \\
\hline $\begin{array}{l}\text { Os conceitos químicos para tomada de decisões que concernem problemas ambientais, energéticos e } \\
\text { sociais são discutidos na disciplina? }\end{array}$ \\
\hline $\begin{array}{l}\text { Existem diferenças entre as estratégias didáticas utilizadas em disciplinas dos cursos } \\
\text { interdisciplinares e em cursos de formação específica? }\end{array}$ \\
\hline Quanto às questões didáticas, o projeto pedagógico apresenta problemas de execução? \\
\hline Quanto às questões de conteúdo científico, o projeto pedagógico apresenta problemas de execução? \\
\hline São inseridas as relações entre química e tecnologia nas disciplinas dos cursos interdisciplinares? \\
\hline A disciplina tem como objetivo apresentar conceitos básicos da Química? \\
\hline Existe material didático adequado para a disciplina? \\
\hline As avaliações refletem a preocupação com uma formação interdisciplinar e sistêmica? \\
\hline Os experimentos desenvolvidos contribuíram para formação de um aluno autônomo? \\
\hline
\end{tabular}

Fonte: elaborado pelos autores.

Documentos oficiais, como Projeto Pedagógico Institucional (PPI), Plano de Desenvolvimento Institucional (PDI), Projeto Pedagógico de Curso (PPC) do Bacharelado em Ciência e Tecnologia da UFABC nas suas versões 2006, 2007-2008, 2009, normativas internas da universidade assim como regulamentações legais externas à universidade foram analisados com o objetivo de procurar as formações discursivas em que se encontram os enunciados de interdisciplinaridade e os regimes de verdade propostos por tais práticas, colaborando para a análise de discurso na perspectiva foucaultiana realizada nos discursos de interdisciplinaridade e formação superior na UFABC.

Grafos foram construídos utilizando os softwares livres Cytoscape 3.1.1 (CYTOSCAPE CONSORTIUM, 2017) e Gephi 0.8.2-beta (GEPHI, 2017) de maneira a colaborar com a compreensão da organização sistêmica das unidades curriculares propostas no PPC do Bacharelado em Ciência e Tecnologia da UFABC. Cada nó cristaliza uma unidade curricular, interligada pelas arestas, possíveis relações direcionadas entre os conteúdos destacados nos planos de ensino das unidades curriculares obrigatórias. O peso de cada nó no grafo mede o número de arestas que 
dele partem ou chegam, enquanto o pagerank estabelece, a partir da quantidade e da qualidade de relações, a importância dos nós para o grafo (OTTE; ROUSSEAU, 2002).

O objetivo é estabelecer pontos de reflexão, a partir do referencial proposto por Gilles Deleuze e Felix Guattari, sobre os discursos pedagógicos e científicos utilizados para a construção e execução do currículo de formação interdisciplinar proposto pela UFABC, com ênfase no Bacharelado em Ciência e Tecnologia; e assim sugerir alguns pontos de fuga que permitirão ir além das relações de poder estabelecidas por tais discursos.

\section{Projeto de formação superior interdisciplinar}

Interdisciplinaridade, como descrita no projeto pedagógico da UFABC, é entendida como uma técnica pela qual um determinado problema é "atacado" pela articulação de várias unidades curriculares, valorizando, assim, o trabalho em equipe e investigativo (UNIVERSIDADE FEDERAL DO ABC, 2006). Mas as características principais apontadas por Fazenda (1994) e Klein (1998) também estão presentes no projeto da UFABC: trabalho colaborativo e integrativo, permeado por temas e problemas geradores (observado na organização das unidades curriculares por eixos); relação do conhecimento com os problemas sociais, econômicos e ambientais (indicados na presença de unidades curriculares da área de Humanidades); flexibilidade curricular (observável majoritariamente na exigência de cumprimento de baixa carga horária em créditos obrigatórios). A execução deste projeto envolve um esforço na direção de uma atitude interdisciplinar, como explicado por Fazenda (1994), de fatores internos à universidade (liberdade curricular, práticas pedagógicas integradoras, lideranças, compromisso e formação do corpo docente, etc.), como identificado por Knight et al. (2013).

Neste trabalho, entende-se interdisciplinaridade como um movimento, uma disposição para o novo, gerada na tensão entre dois ou mais campos do saber produzida pela sua limitação individual para produzir uma resposta complexa satisfatória. Idealmente, os novos saberes produzidos alteram a estrutura epistemológica das ciências de origem e quando tais alterações singularizam-se, há estratificação em uma nova disciplina.

A defesa de Marchelli (2007) de que a interdisciplinaridade na UFABC é assumida como resgate da integridade do conhecimento pode ser dissolvida: a flexibilidade curricular estabelece um currículo singular por permitir o encontro de unidades curriculares que são realizadas a partir do desenho das trajetórias individuais. Desta maneira, a individualização pulveriza o conhecimento ao invés de unificá-lo.

Individualizar, ainda que parcialmente, o currículo de modo que o aluno possa desenhar sua formação profissionalizante de acordo com sua vocação e suas aspirações. Para isso é necessário um elevado grau de flexibilidade da matriz curricular da Universidade. (UNIVERSIDADE FEDERAL DO ABC, 2006, p. 11).

Ao atribuir ao curso interdisciplinar a possibilidade de conhecer cada vez mais do mundo que o cerca, LA2 assume o discurso de unificação do conhecimento:

Quanto mais abrangente o conbecimento que ele tem, maior o conbecimento de mundo. Se ficar apenas na sua área, é muito limitado. Não tem como você entender o mundo, se você só estuda uma área especifica do conhecimento. [LA2]. 
Dentro da perspectiva de reorganização holística do conhecimento citada por LA2, a estrutura organizacional da UFABC dá-se não pelos tradicionais departamentos disciplinares, mas em centros, pretendendo "uma interlocução permanente entre os docentes e discentes trabalhando numa forma interdisciplinar" (UNIVERSIDADE FEDERAL DO ABC, 2006). Os centros - de ciências naturais e humanas $(\mathrm{CCNH})$; de matemática, computação e cognição (CMCC); de engenharia, modelagem e ciências sociais aplicadas (CECS) - foram criados na tentativa de retratar as ações de descobrir (CCNH), sistematizar (CMCC) e inventar (CECS), ações entendidas como fundamentais a quaisquer atividades universitárias, ainda que em diferentes níveis, e encorajariam a formação de uma cultura interdisciplinar. No entanto, desde sua fundação, a UFABC adotou como estrutura administrativa as tradicionais pró-reitorias as quais, atualmente, representam o reitor nas áreas de graduação, pós-graduação, pesquisa, extensão, ações afirmativas e assuntos comunitários, administração (UNIVERSIDADE FEDERAL DO ABC, 2014). Tal esquema de gestão, aponta ID, não colabora com as possibilidades interdisciplinares de produção de conhecimento e de ensino, já que hierarquizam as ações administrativas. É um bom exemplo de como a UFABC poderia ampliar seu aspecto experimental, fronteiriço.

Eu tentei fazer isso aqui mas não consegui. Uma reorganização. Eu acho que não deve ter uma pró-reitoria de graduação ou uma pró-reitoria de pesquisa. Deveria ser apenas uma pró-reitoria de ensino e pesquisa com uma divisão de pós-graduação e uma de graduação. Porque na medida em que você começa a faz̧er essa divisão começa a introduz̨ir a ideia de separação entre ensino e pesquisa. [ID].

\section{Interdisciplinariz-ação}

No caso do Bacharelado em Ciência e Tecnologia, as unidades curriculares obrigatórias representam explicitamente conteúdos curriculares apresentados de uma forma interdisciplinar, organizadas por eixos temáticos que atravessam o currículo para além das unidades curriculares dos campos tradicionais do saber. Tal abordagem de reorganização curricular é uma estratégia que se correlaciona com a proposta unificadora dos saberes que não abdica dos saberes disciplinares na construção holística do conhecimento, nas palavras de ID.

\footnotetext{
É preciso que haja uma reorganização desse conhecimento. Essa foi a motivação para o plano pedagógico da UFABC: “Como reorganizar?” Não é destruir o que está agora, é reorganizar. Quais são os grandes pontos? A partir dai surgiu essa proposta no comitê de implantação da UFABC. [ID].
}

Aos seis eixos temáticos em que se organizam as unidades curriculares obrigatórias do Bacharelado em Ciência e Tecnologia (BC\&T), na versão 2009 de seu Projeto Pedagógico de Curso (PPC) foram inseridas unidades curriculares de bases (Bases Matemáticas e Bases Computacionais da Ciência) que proporcionariam "[...] um estudo diferente de uma revisão do segundo grau, por abordar conteúdos permeados por experimentos numéricos trabalhados de forma agregada e por meio de ferramentas mais modernas como gráficos e planilhas, além da contextualização com a realidade" (UNIVERSIDADE FEDERAL DO ABC, 2008, p. 2). 
Os eixos às quais as unidades curriculares pertenceriam não foram apresentados no PPC/BC\&T (UNIVERSIDADE FEDERAL DO ABC, 2009), mas, na ata da reunião que discutiu a revisão que daria origem a esse projeto, aparecem indícios de que já houve alguma especialização na elaboração das novas ementas (UNIVERSIDADE FEDERAL DO ABC, 2008). No entanto, o edital para processo seletivo do programa de monitoria acadêmica (UNIVERSIDADE FEDERAL DO ABC, 2012) institui aos eixos as suas respectivas unidades curriculares. Os pesos atribuídos aos eixos nas unidades curriculares obrigatórias do curso podem ser computados a partir das cargas horárias atribuídas às unidades curriculares, conforme descrito no PPC/BC\&T (UNIVERSIDADE FEDERAL DO ABC, 2009). Nota-se que o eixo de Representação e Simulação representa 20\% , o eixo de Energia 18\%, o eixo de Processos de Transformação 16\%, o eixo de Informação e Comunicação $12 \%$, o eixo de Humanidades 7\% e as Bases $14 \%$ da carga horária presencial obrigatória do curso.

O grafo da Figura 1 foi construído a partir das possíveis relações entre os conteúdos destacados nos planos de ensino das unidades curriculares obrigatórias. Essas relações foram estabelecidas como um exemplo possível dos muitos outros encontros que podem ser compreendidos das unidades curriculares do BC\&T. Isso não significa que as análises oriundas desses grafos são compreendidas como uma verdade última, mas como um direcionamento possível para compreensão desse sistema inter-relacionado.

Figura 1. Grafo elaborado a partir de algumas das relações possíveis (arestas), estáticas momentaneamente, entre as unidades curriculares obrigatórias do BC\&T (nós)

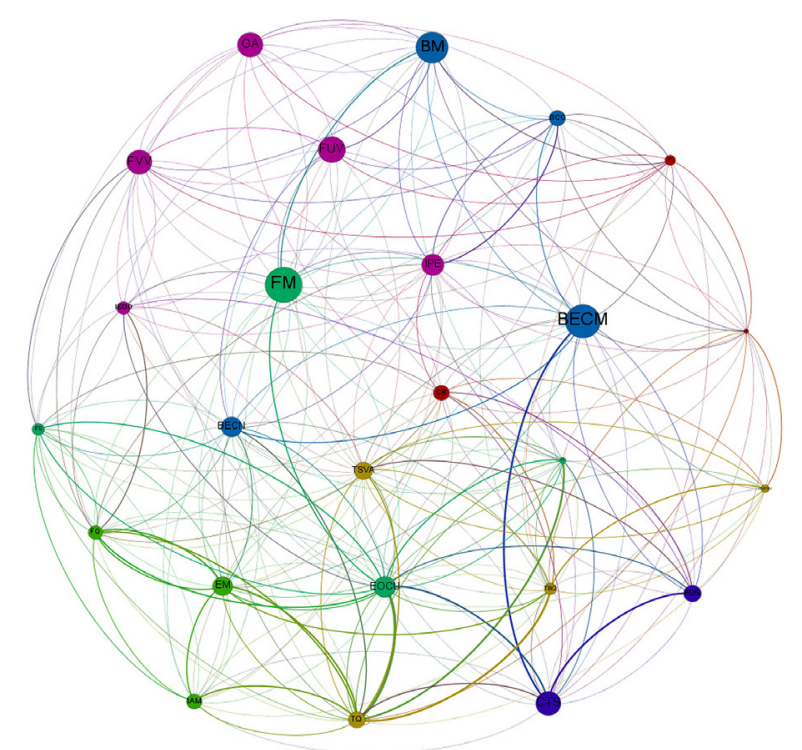

Legenda: Cada eixo temático está representado por uma cor diferente: Bases em azul, Estrutura da matéria em verde, Energia em verde escuro, Processos de Transformação em amarelo, Representação e simulação em lilás, Informação e comunicação em vermelho e Humanidades em roxo. Os rótulos nos vértices correspondem às unidades curriculares.

Fonte: elaborado pelos autores. 
Para o grafo da Figura 2, as unidades curriculares foram agrupadas nos eixos, para que as relações entre eles pudessem ser melhor visualizadas. Há uma grande concordância entre o peso dos eixos no estabelecimento das relações possíveis entre as unidades curriculares obrigatórias do BC\&T e a proporcionalidade da carga horária atribuída a elas, reforçando a ideia de que esses conjuntos de unidades curriculares (eixos da Representação e Simulação e da Energia) são fundamentais para o desenvolvimento do curso. Nesse aspecto, é um Bacharelado mais em Ciência e menos em Tecnologia (BC\&t).

As unidades curriculares de Bases e de Representação e Simulação têm forte contribuição para manutenção do grafo, o que pode indicar (associado à alta carga horária percentual desses eixos) um caráter altamente positivista do currículo. As unidades curriculares com maior peso - portanto, são as que mais estabelecem relações no grafo -, por eixo, são: Bases Epistemológicas da Ciência Moderna (BECM); Energia: Origens, Conversão e Usos (EOCU); Estrutura da Matéria (EM); Ciência, Tecnologia e Sociedade (CTS); Comunicação e Redes (CR); Transformações Químicas (TQ); e Introdução à Probabilidade e à Estatística (IPE).

Figura 2. Grafo das unidades curriculares obrigatórias do BC\&T organizados por eixos em função do peso que atribuem ao grafo

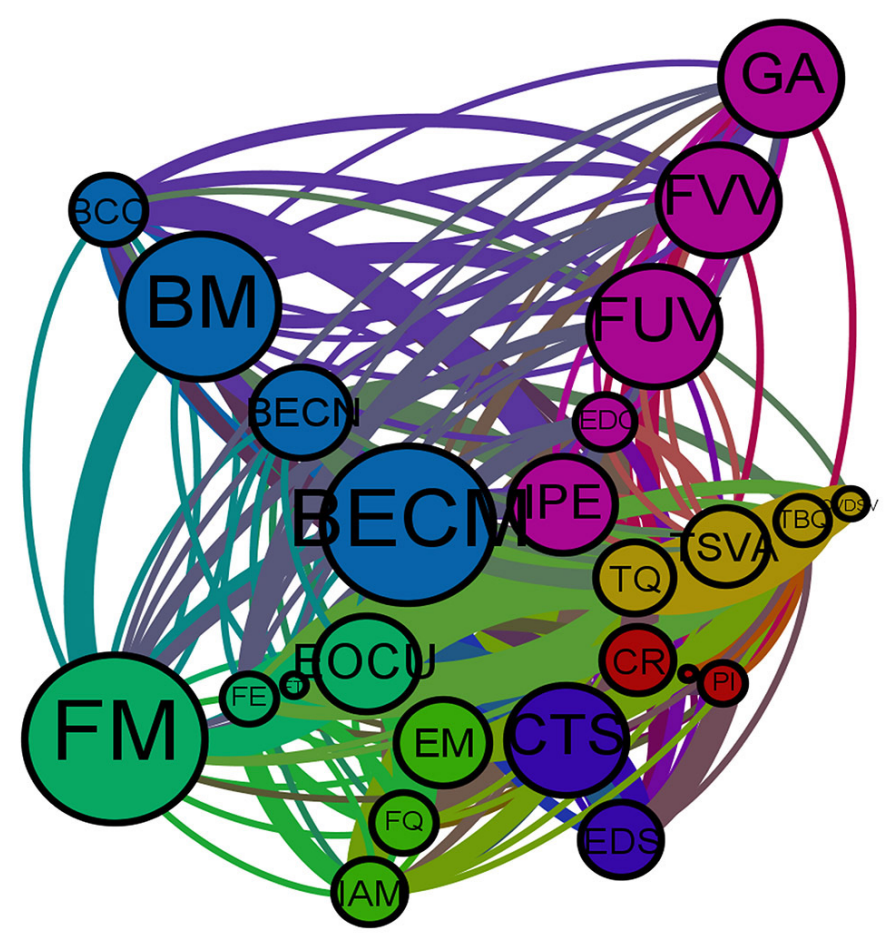

Legenda: As esferas nas unidades curriculares representam o pagerank (PAGE et al., 1998) - ou seja, a importância das relações estabelecidas pelas arestas de cada nó na manutenção do grafo - de cada uma delas nas relações estabelecidas.

Fonte: elaborada pelos autores. 
Unidades curriculares sugeridas para serem cursadas no fim do eixo (UNIVERSIDADE FEDERAL DO ABC, 2009) são encontradas no grupo das unidades curriculares com maior peso para o grafo. Poderia se assumir que a vivência no eixo (aquisição de conhecimentos fundamentais prévios) permite o estabelecimento das relações pretendidas ao final do curso?

As unidades curriculares que mais contribuem para a estrutura do grafo - fazendo delas mais importantes para manutenção da rede interdisciplinar proposta pelo conjunto de unidades curriculares obrigatórias - por eixo são: Bases Epistemológicas da Ciência Moderna (BECM); Fenômenos Mecânicos (FM); Estrutura da Matéria (EM); Ciência, Tecnologia e Sociedade (CTS); Comunicação e Redes (CR); Transformações dos Seres Vivos e Ambiente (TSVA); e Funções de Uma Variável (FUV). As unidades curriculares 'fundamentais' aparecem como as mais importantes para manutenção da estrutura do grafo - elas são necessárias para que o conjunto das relações no curso seja possível. Há uma alta relação entre as unidades curriculares do eixo de Processos de Transformação, indicando uma grande relação de trocas entre essas unidades curriculares, razoavelmente isolado do conjunto de relações do grafo.

Assim, são elas as unidades curriculares que mais contribuem para interdisciplinaridade do projeto - pode-se assumir que a vivência no eixo permite que conhecimentos fundamentais sejam adquiridos durante o percurso que possibilita estabelecer relações críveis ao final do caminho. Unidades curriculares mais importantes para manutenção da estrutura do grafo são mais fundamentais - elas são necessárias para que as relações no curso sejam possíveis. Todavia, o currículo que contempla áreas do saber que não se encontram explicitamente relacionadas no projeto pedagógico do curso exige do corpo docente um esforço para explicitar as relações entre os conteúdos encontrados em uma mesma unidade curricular ou entre as unidades curriculares, conforme a fala de LD1:

A sensação que às vezes eu tenho é que muitas vezes a gente fica na posição de equilibrista, no sentido de que você tem que justificar a cada momento o que você quer com aquela disciplina. Por outro lado, se você pensa até nesse sentido dá um gostinho "agridoce". No sentido que você tem que mostrar pro aluno que não necessariamente aquilo é parte de algo que não vai ter relação com ele ou com a vida dele. [LD1].

Essas análises reforçam a ideia de que o entendimento de período ideal para cursar as unidades curriculares não apenas funciona como dispositivo de controle do tempo e da oferta, mas também amarram o currículo de maneira não institucionalizada: pré-requisitos formais não são divulgados, porém, há um entrelaçamento virtual entre as unidades curriculares que as colocam numa sequência concreta. A autonomia de cada unidade curricular é perdida.

Pelo gráfico das correlações das unidades curriculares do BC\&T, podemos identificar dois grandes grupos:

- Unidades curriculares com caráter tecnológico e/ou de ciência aplicada: Física Quântica, Fenômenos Eletromagnéticos, Estrutura da Matéria, Interações Atômicas e Moleculares, Transformações Químicas, Energia: Origens, Conversão e Uso, Comunicação e Redes, Introdução às Equações Diferenciais Ordinárias, Base Experimental das Ciências Naturais, Fenômenos Térmicos, Transformações Bioquímicas, Ciência, Tecnologia e Sociedade, Origem da Vida e Diversidade dos Seres Vivos, Transformações nos Seres Vivos e Ambiente (agrupadas no canto superior esquerdo). 
- Unidades curriculares com caráter fundamental e/ou lógico-matemático: Natureza da Informação, Estrutura e Dinâmica Social, Processamento da Informação, Fenômenos Mecânicos, Bases Epistemológicas da Ciência Moderna, Geometria Analítica, Introdução à Probabilidade e à Estatística, Bases Matemáticas, Bases Computacionais da Ciência, Funções de Uma Variável, Funções de Várias Variáveis (agrupadas no canto inferior direito).

Figura 3. Gráfico de correlação das unidades curriculares obrigatórias do BC\&T a partir das relações estabelecidas entre suas ementas

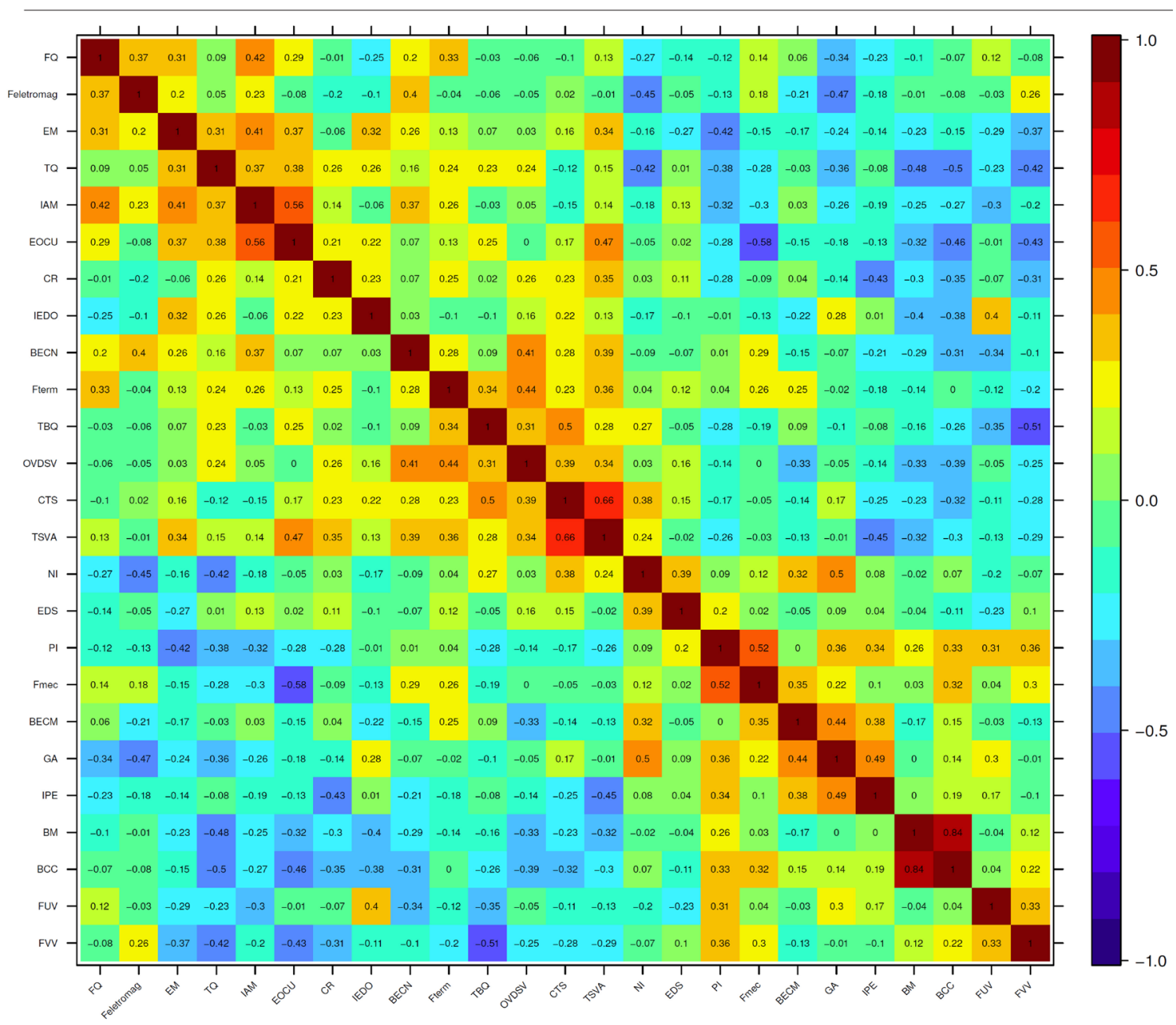

Legenda: Quanto mais próximo de 1 estiver o valor absoluto da medida indicada na célula, maior a correlação entre as disciplinas.

Fonte: elaborada pelos autores. 
As análises das representações das Figuras 1, 2 e 3 permitem qualificar as relações existentes do conjunto de unidades curriculares obrigatórias do BC\&T, identificando maior peso tanto na carga horária quanto nas relações existentes entre unidades curriculares dos eixos mais fundamentais (lógico-matemático: Representação e Simulação; científico-aplicado: Energia). Também se consegue identificar as unidades curriculares mais importantes para que as relações possíveis no curso se mantenham, assim como as unidades curriculares mais relacionáveis: estabeleceu-se uma sequência que corrobora a ideia de período ideal, desconstruindo a ideia de que neste currículo as unidades curriculares são autônomas e independentes. Para o corpo discente, aponta LA1, o conjunto de unidades curriculares relacionados para a formação do/a bacharel/a em Ciência e Tecnologia fazem parte fundamental do currículo ainda que não haja motivação para explorar esta diversidade de caminhos propostos: "Para mim algumas matérias são tomadas como parte da trajetória. Algumas a gente até gosta, aprende a gostar, né? Mas não é a maioria”. [LA1].

Uma possível atitude interdisciplinar do docente na UFABC esbarra em outras forças que limitam sua ação (e deslocam o trabalho na universidade de uma relação romantizada) e tradicionalizam a UFABC: burocracias institucionais, controle do tempo, exercício de outras funções-docente, formação inicial, assim como os discursos oficiais, as normativas e regulamentações internas. (XAVIER, 2015).

\section{Trans-rizomatizar}

É possível pensar em uma alternativa ao processo moderno de produção de saberes apoiando-se na produção teórica de Deleuze e Guatarri. Para os autores, não existe um pressuposto último que sustenta todo o conhecimento produzido, que se ramifica conforme especialização da área. Tal especialização costuma ser relacionada com a analogia do crescimento dos ramos de uma árvore: no aumento da abrangência das explicações possíveis do mundo, unificam-se em sua compreensão. A unidade curricular específica não pretende abandonar conhecimentos genéricos, mas os compor em sua unidade. No campo da educação, disciplina tem sido classicamente compreendida como um "Conjunto específico de conhecimentos que tem características próprias nos modos de sua construção histórica, nos campos do ensino e da formação profissional, na definição dos conteúdos e dos métodos de abordar seu objeto de estudo" (BORDAS, 2007, p. 74).

No entanto, essa ingênua opção não permite compreender a insistência da UFABC, pretendida inovadora em sua concepção pedagógica, no formato tradicional disciplinar. A opção conceitual tomada nesta pesquisa pauta-se na compreensão de que uma disciplina é um disposto o qual

[...] designa todo um conjunto de práticas discursivas e não discursivas cujos elementos (de diferentes naturezas, como: discursos, instituições, teorias, regulamentos, e leis, enunciados científicos, práticas sociais, proposições filosóficas, arquiteturas, etc.) são heterogêneos mas se mantêm conectados em uma rede de relações. [...] A rede de relações que mantém certas práticas e correlatas instituições articuladas entre si e cuja racionalidade desempenha funções cujo objetivo principal é fazer funcionar ou manter 
o poder de uns sobre os outros, a ação de uns sobre as ações dos outros. (VEIGA-NETO, 2008, p. 145).

Ao organizar vários elementos em uma rede de relações que, articuladas, racionalizam o funcionamento de relações de poder pré-estabelecidas, as disciplinas reforçam modos de formação tradicional, falhando como projeto de formação pós-moderno. Os processos de especialização disciplinar organizam sistemas arborescentes por organizar quaisquer novos conteúdos dentro de uma malha organizada de sistemas de categorização mutáveis, seja pela alteração das fronteiras das categorias, seja pela criação de uma nova categoria. A especialização dos saberes vai buscar do desconhecido e vai enquadrá-los no retículo disciplinar, de modo que nada possa se colocar fora de seu alcance e do seu domínio. Tal absorção resulta ou em novas fronteiras e uma nova categoria para abrigar a novidade ou em um novo caso dentro de uma categoria já existente, que jamais é a que promoveu a inclusão (VEIGA-NETO, 2002).

Novos ramos ou novas especializações são resultado do processo moderno de manutenção disciplinar. As disciplinas, de acordo com Foucault (2012), vão além da criação de epistemes categorizadas, mas organizam o controle dos corpos numa sociedade disciplinada.

Este novo mecanismo de poder apoia-se mais nos corpos e seus atos do que na terra e seus produtos. E um mecanismo que permite extrair dos corpos tempo e trabalho mais do que bens e riqueza. E um tipo de poder que se exerce continuamente através da vigilância e não descontinuamente por meio de sistemas de taxas e obrigações distribuídas no tempo; que supõe mais um sistema minucioso de coerções materiais do que a existência física de um soberano. Finalmente, ele se apoia no princípio, que representa uma nova economia do poder, segundo o qual se deve propiciar simultaneamente o crescimento das forças dominadas e o aumento da força e da eficácia de quem as domina. (FOUCAULT, 2012, p. 187).

Nesta pesquisa, não se entendeu ingenuamente que a escolha por outro tipo de identificação - unidade curricular - possa alterar o caráter disciplinador da Educação. Deleuze (2013) identifica no século XX o surgimento de um novo tipo de organização social, as sociedades de controle. Em crise (haja vista que foram criadas para e criaram o empreendimento moderno),

As disciplinas não desaparecerão, mas a lógica disciplinar está sendo recoberta pelas técnicas de controle, tudo isso de modo a manter os riscos sociais em níveis minimamente seguros. Os objetivos dessa nova vigilância deixam de almejar o disciplinamento e passam a registrar as informações acerca de nossas ações, de modo que possa, a qualquer momento, conferir, fiscalizar, examinar. Tal sistema de controle interconectado, facilitado e barateado graças aos recursos da telemática, produz uma atitude dócil e resignada, atendendo disciplinarmente tudo o que exigem de nós, ainda que sejamos flexíveis e entramos estrategicamente no jogo (provoca nos sujeitos sobre o qual atua artimanhas e artifícios de escape, evasiva e - no 
limite da relação entre a própria subjetividade e as exigências do sistema - a recusa). (VEIGA-NETO, 2008, p. 146).

A visão rizomática da estrutura do conhecimento não estabelece nem início nem fim para o saber. O conhecimento assume a forma fascicular, em que não há ramificações, mas pontos que se originam de qualquer parte, e se dirigem para quaisquer outros pontos. A multiplicidade surge como linhas independentes que representam modos inventados e reinventados de construir realidades, que podem ser desconstruídos. Assim, o rizoma pode se conectar a quaisquer pontos (princípio da conexão e heterogeneidade), não mantém relação com o último unitário e verdadeiro (princípio da multiplicidade), quebra com os processos rígidos de significação (princípio da ruptura assignificante), é sempre esboço incompleto (princípio de cartografia e de decalcomania).

Em oposição à ideia de integração disciplinar (POMBO, 2004, p. 153), em que "se espera que a unidade da linguagem das ciências não tenha que ser 'imposta' mas possa ser obtida sob a forma de uma 'progressiva uniformização', pelo próprio desenvolvimento da prática científica”, aposta-se nas multiplicidades criadoras do rizoma, permitindo que novos jeitos de pensar e viver avancem a lógica moderna das sociedades disciplinares e, com sorte, a lógica pós-moderna das sociedades de controle.

No que diz respeito à gestão deste modelo de formação (e de trabalho docente), G1 apresenta a possibilidade de uma autorregulação do modelo flexível, para que permita a proposição de políticas que direcionam a formação em que as singularidades passam a existir:

Então, me parece que o grande dilema desse modelo (e a gente precisa aprender a fazer isso) é garantir que ele continue sendo dinâmico. Algo que foi pensado e não funciona pode ser mudado [...] A minha leitura é que esse modelo precisaria de um grupo de estatísticas e análise que ficassem o tempo todo monitorando, mapeando, o que dá certo, o que não dá certo, pensando novas estratégias para melhorar alguns pontos. [G1].

Possíveis relações entre unidades curriculares diferentes, únicas, para cada aluno. Possíveis e móveis relações estabelecidas entre todos os saberes para cada unidade curricular. Possíveis intensidades de formação, possíveis linhas de fuga, possíveis organizações que se apagam e se constroem a cada momento. No grafo da Figura 1, essas relações formam um mapa que rapidamente pode se desfazer. Novas relações podem ser estabelecidas. As margens desse mapa não são vazias, como infelizmente o grafo limita. As suas margens também apresentam novas relações, alteradas pelas trajetórias singulares dos alunos pelas unidades curriculares de sua escolha. Essas margens, essas relações, alteram-se na prática docente, nas revisões curriculares, na relação com a formação profissional. Unidades curriculares que molarizam conhecimentos mas, em seus encontros singulares, propiciam linhas de fuga que desestabilizam os campos disciplinares do saber. Estratégias hierarquizantes que estratificam os platôs de saber-sentirfazer (FERRAÇO, 2005).

Estamos na idade dos objetos parciais, dos tijolos e dos restos. Já não acreditamos nesses falsos fragmentos que, como os pedaços de uma está- 
tua antiga, esperam ser completados e reagrupados para comporem uma unidade que é, também, a unidade de origem. Já não acreditamos numa totalidade original nem sequer numa totalidade de destinação. (DELEUZE; GUAT'TARI, 2011b, p. 62).

Pensar o rizoma em educação é colocar em prática a compreensão de que existem múltiplas formas de devir, que dialogam entre si dentro de contextos sociais, históricos e geográficos específicos. Os saberes criam conexões múltiplas de elementos com vários campos do conhecimento, comunicam-se entre si, estabelecem redes interligadas sempre cambiantes, nômades, momentâneas, locais. Talvez seja um bom caminho para se construir interdisciplinaridade na pós-modernidade: apostar em uma pedagogia rizomática (LINS, 2005). Talvez alterar o perfil arborescente de uma epistemologia moderna para um perfil rizomático de uma epistemologia pós-moderna. Identificam-se tais possibilidades já que os discursos explorados nas análises desta pesquisa localizam a interdisciplinaridade em unidades curriculares pretendidas, independentes de conhecimento propriamente interdisciplinar (as unidades curriculares obrigatórias do BC\&T) e como um currículo flexível que, articulado por diferentes saberes em conjunto, produz novos sujeitos (as relações implícitas entre as unidades curriculares). Entretanto, apenas a interdisciplinaridade não permite os fluxos livres e não-hierárquicos característicos do rizoma.

A transdisciplinaridade é mais representativa deste modelo proposto nesta pesquisa. Bevilacqua (2011) já adiantava que a interdisciplinaridade traz em si um "gene de autodestruição": à medida que as interações propiciariam a criação de novas áreas de saber que, no início de sua existência ainda estariam altamente relacionadas com outras, após algum tempo de maturação, cristalizariam-se em campos do saber independentes. "A interdisciplinaridade caminha para a transdiciplinaridade” (BEVILACQUA, 2011, p. 798), possibilitando uma agregação temática dos campos de saber em cooperação plena para resolução dos problemas da sociedade.

Entre as coisas não designa uma correlação localizável que vai de uma para a outra reciprocamente, mas uma direção perpendicular, um movimento transversal que as carrega uma e outra, riacho sem início nem fim, que rói suas duas margens e adquire velocidade no meio. (DELEUZE; GUATTARI, 2011a, p. 49).

A transdisciplinaridade, define Ritto (2010), é uma atitude transgressora dos binarismos pela unidade aberta que abarca tanto o universo (com seus diferentes níveis de realidade) quanto o homem (em seus diferentes níveis de consciência). Tal unidade aberta entre objeto e sujeito transdisciplinares se traduz pela orientação coerente do fluxo de informação, que atravessa os níveis de realidade, do fluxo de consciência e os níveis de percepção.

D'Ambrosio (2012) defende que a transdisciplinaridade exige um reconhecimento de que não há espaços ou tempos culturais privilegiados que permitam hierarquizar os diversos complexos de explicações e de convivência com a realidade. Argumenta que a globalização provocou a necessidade de desenvolvimento de trabalhos em grupo, de estudos comparados e de áreas híbridas de investigação. Nesse novo cenário, propõe que as universidades reorganizem seus currículos para privilegiar unidades tutoriais e interdisciplinares em paralelo com o ensino tradicional, com drástica redução de carga horária. Sua proposta deve envolver os 
alunos, desde o ingresso na universidade, em processos criativos, associados a pesquisadores, laboratórios, projetos, o que traz como consequência repensar a obsolescência das disciplinas e de seus pré-requisitos. O espaço se abriria para as oportunidades de resolução de questões complexas, acompanhando o surgimento de perspectivas holísticas para compreensão de problemas em áreas híbridas de investigação que não conseguem ser resolvidas pela tradicional compartimentalização dos conteúdos.

Santos (2005) defende que, na transdisciplinaridade, há diálogo e uso de diferentes conceitos, mas mantém a autorreferencialidade através da multirreferencialidade. Transgredindo as fronteiras de cada ciência, produz um novo saber que devolve sentido à percepção humana do mundo. Este macroconceito criado no processo transdisciplinar está em contínua renovação, é sempre provisório. Seria a transdisciplinaridade uma possibilidade aberta para a produção de uma educação rizomática?

Gallo (1997) ressalta que muitas das propostas interdisciplinares esbarram em problemas, por exemplo, a formação tradicional dos professores, que precisam vencer suas fronteiras conceituais para estabelecer relações com outros campos do conhecimento. O autor defende a transversalidade rizomática em oposição às integrações horizontais e/ou verticais entre as ciências: ela seria matriz da mobilidade rizomática estabelecendo a abrangência necessária de todo o "horizonte de eventos". Assim, o exercício da liberdade de construção dos percursos formativos e a ausência de pré-requisitos, que permite quaisquer arranjos temporais das unidades curriculares obrigatórias interdisciplinares, eliminam as hierarquizações horizontais ou verticais arborescentes, para um modelo de distribuição com crescimento rizomático, transdisciplinar.

\section{Considerações finais}

No que se trata do conceito de interdisciplinaridade, concepções integradoras direcionam numa compreensão da interdisciplinaridade como estratégia para unificação do conhecimento que, tomadas em último nível, podem ser antidisciplinares. Destoando dessa concepção, associa-se uma postura atitudinal como peça fundamental para correta execução do projeto. A estrutura administrativa não departamental da UFABC pretende colaborar com o exercício da interdisciplinaridade, mas sua estrutura gerencial tradicional impede avanços no sentido de novas práticas de ensino e pesquisa. A comparação de grafos, que apresentam relações possíveis entre as unidades curriculares obrigatórias e a carga horária disponível a elas, evidencia a ênfase fundamental lógico-matemática em detrimento de abordagens científico-tecnológicas.

Pensar e construir uma universidade que se utilize dessas linhas de fuga para rizomatizar as práticas docentes, utilizando como eixos transversais processos essenciais para a universidade, por exemplo, o ensino, a pesquisa e a extensão, para romper a lógica hierarquizante dos processos de ensino-aprendizagem, dos processos gerenciais e representativos. Reelaborar a noção de universidade e, consequentemente, de saber, dando vazão aos saberes locais e nômades, possibilitando formações que vão além dos ritos e das formalidades acadêmicas. Escapar ao uno pela democratização da universidade enquanto multidão. Estas são as apostas para a construção de uma universidade que abandone a lógica arborescente e libere a transversalidade de seu devir-currículo rizomático. 


\section{Referências}

BEVILACQUA, L. Primórdios da área multidisciplinar da Capes e suas influências na pósgraduação e na graduação. In: PHILIPPI JR., A.; SILVA NETO, A. J. Interdisciplinaridade em ciência, tecnologia \& inovação. Barueri: Manole, 2011. p. 785-802.

BORDAS, M. C. A interdisciplinaridade na universidade: possibilidades e limites. In: FRANCO, M. E. D. P.; KRAKHE, E. D. (Org.). Pedagogia universitária e áreas do conhecimento. Porto Alegre: EdiPucrs, 2007. p. 73-93.

CYTOSCAPE CONSORTIUM. Cytoscape: network data integration, analysis, and visualization in a box. Disponível em: <http://www.cytoscape.org/>. Acesso em: 28 mar. 2017.

D’AMBROSIO, U. Transdisciplinaridade. São Paulo: Palas Athena, 2012.

DELEUZE, G. Conversações. 3. ed. Rio de Janeiro: Ed. 34, 2013.

DELEUZE, G.; GUATTARI, F. O anti-Édipo: capitalismo e esquizofrenia 1. 2. ed. Rio de Janeiro: Ed. 34, 2011a.

. Mil platôs: capitalismo e esquizofrenia 2. 2. ed. Rio de Janeiro: Ed. 34, 2011b. v. 1.

FAZENDA, I. C. A. Interdisciplinaridade: história, teoria e pesquisa. Campinas: Papirus, 1994.

- Critical-historical review of interdisciplinar studies in Brazil. Association for

Integrative Studies Newsletter, Clinton Township, v. 17, n. 1, p. 2-9, 1995.

FERRAÇO, C. E. Currículo, formação continuada de professores e cotidiano escolar: fragmentos de complexidades das redes vividas. In: . (Org). Cotidiano escolar, formação de professores(as) e currículo. São Paulo: Cortez, 2005. p. 15-42.

FISCHER, R. M. B. Trabalhar com Foucault. Belo Horizonte: Autêntica, 2012.

FOUCAULT, M. A arqueologia do saber. 8. ed. Rio de Janeiro: Forense Universitária, 2013.

Microfísica do poder. Rio de Janeiro: Graal, 2012.

GALLO, S. Conhecimento, transversalidade e educação: para além da interdisciplinaridade. Impulso, Piracicaba, v. 10, n. 21, p. 115-33, 1997.

GEPHI: the open graph viz platform. Disponível em: < https://gephi.org/> Acesso em: 28 mar. 2017.

JAPIASSÚ, H. Interdisciplinaridade e patologia do saber. Rio de Janeiro: Imago, 1976. JAPIASSÚ, H.; MARCONDES, D. Dicionário básico de filosofia. 4. ed. Rio de Janeiro: Zahar, 2006.

KLEIN, J. T. Ensino interdisciplinar: didática e teoria. In: FAZENDA, I. Didática e interdisciplinaridade. 13. ed. Campinas: Papirus, 1998. p. 109-132. 
KNIGHT, D. B. et al. Understanding interdisciplinarity: curricular and organizational features of undergraduate interdisciplinary programs. Innovative Higher Education, Dordrecht, v. 38, n. 2, p. 143-158, 2013.

LINS, D. Mangue’s school ou por uma pedagogia rizomática. Educação \& Sociedade, Campinas, v. 26, n. 93, p. 1229-1256, 2005. Disponível em: <http://www.scielo.br/pdf/es/ v26n93/27277.pdf >. Acesso em: 29 mar. 2017.

MARCHELLI, P. S. O novo projeto universitário no Brasil e o foco no currículo interdisciplinar. Revista e-Curriculum, São Paulo, v. 3, n. 1, 2007. Disponível em: < http:// revistas.pucsp.br/index.php/curriculum/article/viewFile/3195/2117>. Acesso em: 29 mar. 2017.

OTTE, E.; ROUSSEAU, R. Social network analysis: a powerful strategy, also for the information sciences. Journal of Information Science, London, v. 28, n. 6, 441-453, dez. 2002.

PAGE, L. et al. The PageRank citation ranking: bringing order to the web. [S.l.]: eprints, 1998. Disponível em: <http://ilpubs.stanford.edu:8090/422/1/1999-66.pdf>. Acesso em: 29 mar. 2017.

POMBO, O. Interdisciplinaridade: ambições e limites. Lisboa: Relógio D’água, 2004.

RITTO, A. C. A. Transdisciplinaridade: as várias verdades, as diferentes lógicas. In: NEFFA, E.; RITTO, A. C. A. Percepção transdisciplinar: uma construção coletiva. Rio de Janeiro: EdUERJ, 2010. p. 23-42.

SANTOS, A. Teorias e métodos pedagógicos sob a ótica do pensamento complexo. In: LIBÂNEO, J. C.; SANTOS, A. Educação na era do conhecimento em rede e transdisciplinaridade. Campinas: Alínea, 2005. p. 63-82.

UNIVERSIDADE FEDERAL DO ABC. Boletim de serviço n. 347. Santo André, 2014. Disponível em: < http://www.ufabc.edu.br/images/stories/comunicare/boletimdeservico/ boletim_servico_ufabc_347.pdf>. Acesso em: 17 ago. 2014.

. Edital $n^{\circ}$ 151, de 09 de novembro de 2012. Programa de Monitoria Acadêmica. [Santo André], 2012. Disponível em: < http://prograd.ufabc.edu.br/images/pdf/121112_ monitoria_academica.pdf $>$. Acesso em: 2 nov. 2014.

Projeto pedagógico. [Santo André], 2006. Disponível em: <http://www.ufabc. edu.br/images/imagens_a_ufabc/projetopedagogico.pdf >. Acesso em: 30 mar. 2017.

Síntese do projeto pedagógico do curso bacharelado em ciência e tecnologia. Santo André, 2009. Disponível em: < http://prograd.ufabc.edu.br/images/pdf/27-01-10_ projeto-pedagogico_bct.pdf>. Acesso em: 15 jul. 2014.

UNIVERSIDADE FEDERAL DO ABC. Conselho de Ensino e Pesquisa. Ata $\mathbf{n}^{\mathbf{0}}$ 03/2008. Santo André, 2008. Disponível em: <http://www.ufabc.edu.br/images/consepe/ atas/2008_17-06-ord.pdf >. Acesso em: 30 mar. 2017. 
VEIGA-NETO, A. Crise da modernidade e inovações curriculares: da disciplina para o controle. Sísifo: revista de ciências da educação, Lisboa, v. 23, n. 79, p. 163-186, ago. 2008. . Currículo e interdisciplinaridade. In: MOREIRA, A. F. B. (Org.). Currículo: questões atuais. Campinas, Papirus, 1997. p. 59-102.

. De geometrias, currículo e diferenças. Educação \& Sociedade, Campinas, v. 23, n. 79, p. 163-186, 2002. Disponível em: < http://dx.doi.org/10.1590/S010173302002000300009>. Acesso em: 29 mar. 2017.

XAVIER, A. M. Flexibilidade curricular, interdisciplinaridade e formação continuada: projeto mol(ecul)ar de formação superior da UFABC. 2015. 219 f. Tese (Doutorado em Ciência e Tecnologia) - Universidade Federal do ABC, Santo André, 2015.

ZUCCO, C.; PESSINE, F. B. T.; ANDRADE, J. B. Diretrizes curriculares para os cursos de química. Química Nova, São Paulo, v. 22, n. 3, p. 454-461, 1999. 